\title{
Evaluation of the erosive capacity of children's beverages on primary teeth enamel: An in vitro study
}

\author{
Daniel-Gheur Tocolini ${ }^{1}$, Mariana Dalledone ${ }^{1}$, João-Armando Brancher ${ }^{2}$, Juliana-Feltrin de Souza ${ }^{3}$, Car- \\ la-Castiglia Gonzaga ${ }^{2}$
}

${ }^{1}$ PhD student, Graduate Program in Dentistry, Universidade Positivo, Curitiba, Brazil

${ }^{2}$ Professor, Graduate Program in Dentistry, Universidade Positivo, Curitiba, Brazil

${ }^{3}$ Professor, Department of Stomatology, Federal University of Paraná Curitiba, Brazil

Correspondence:

Universidade Positivo

Prédio da Pós-Graduação

Rua Prof. Pedro Viriato Parigot de Souza

5300-81280-330-Curitiba-PR-Brasil

carlacgonzaga2@gmail.com

Tocolini DG, Dalledone M, Brancher JA, de Souza JF, Gonzaga CC. Evaluation of the erosive capacity of children's beverages on primary teeth enamel: An in vitro study. J Clin Exp Dent. 2018;10(4):e383-7. http://www.medicinaoral.com/odo/volumenes/v10i4/jcedv10i4p383.pdf

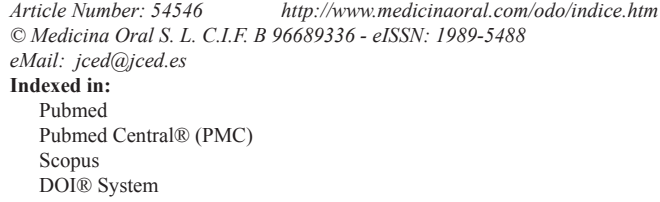

\begin{abstract}
Background: The consumption of acidified beverages, associated with lower mineralization of primary enamel, is the ideal combination for the development and progression of dental erosion. The objective of this study is to analyze the erosive capacity and the surface roughness of primary teeth enamel after exposure to three different brands of grape juices.

Material and Methods: Forty enamel blocks of primary teeth were obtained, attened and polished. They were submitted to initial surface roughness analysis (baseline), and randomly assigned into four groups $(\mathrm{n}=10)$ : NAT: natural grape juice (Campo Largo); IND: industrialized grape juice (Dell Vale Kapo); SOY: soy-based grape juice (Ades); and CONT (control): artificial saliva. Blocks were immersed for 2 min, 3 times per day, for 9 days. During the whole time of the experiment, the enamel blocks were stored in artificial saliva. After the 9 days, the roughness parameters were determined again. The beverages were analyzed for $\mathrm{pH}$ and titratable acidity. Data were statistically analyzed $(\alpha=0.05)$.

Results: The surface roughness did not differ significantly among groups $(p>0.05)$. However, after the immersion in the different grape juices, the surface roughness values increased significantly $(p<0.05)$. The $\mathrm{pH}$ values were weakly correlated to acidity values; NAT showed the highest titratable acidity values than the other juices $(p<$ $0.05)$.

Conclusions: Although the surface roughness values of the experimental groups did not differ from the control group, there was a difference in initial and final roughness in all groups. Grape juices, especially natural, may have an erosive capacity, changing the surface roughness of primary dental enamel.
\end{abstract}

Key words: Dental erosion, beverages, enamel, roughness. 


\section{Introduction}

In recent decades, because of public health measures, there is a clear decline in tooth decay rates in populations of different regions of the planet; however, clinicians began to worry about other changes that affect the hard dental tissue, such as enamel hypomineralization, abrasion and tooth erosion (1-2). Naturally, there is a physiological enamel wear throughout life, but the pathologic tooth wear became prevalent in people of all ages and is especially worrying in primary dentition (3). The loss of the mineral teeth material is caused by a combination of factors, but regarding dental erosion, the main cause is the acid attack on the tooth surface by acids of non-bacterial origin but by intrinsic acids, from diet or even aspirated or inhaled $(4,5)$.

Among the intrinsic acids, the stomach hydrochloric acid, from vomiting or gastroesophageal reflux, and those contained in beverages, are the most important. Studies on the effects of beverages on tooth structure are not recent (6). A meta-analysis study showed a significant association between dental erosion and consumption of acidic drinks (7). Despite the saliva present in the oral cavity mitigates the deleterious effects of acidic beverages, regular consumption of such beverages markedly decreases the saliva buffer capacity, which results in demineralization of tooth structure $(8,9)$.

With regard to children, extra care must be taken because the consumption of acidified beverages, associated with lower mineralization of primary enamel, is the ideal combination for the development and progression of dental erosion. Because the process is slow and progressive, early clinical diagnosis and identification of etiologic factors involved is the key to prevention.

Thus, the aim of this study was to evaluate the surface roughness of primary teeth enamel after exposure to three different brands of grape juices. In addition, $\mathrm{pH}$ and titratable acidity of beverages were evaluated.

\section{Material and Methods}

This study was approved by the Institutional Review Board and used 40 donated primary teeth. The inclusion criteria were primary incisors and molars having at least one of free surfaces healthy allowing the removal of a block of enamel. Teeth without coronary remaining, endodontically treated teeth, and teeth with developmental defects in tooth enamel were excluded.

Enamel blocks were prepared with dimensions of 3 $\mathrm{mm} 2$, were flattened and polished with sandpaper in descending granulation 400,600,1200. The thickness of the blocks was evaluated and standardized in all dimensions using a digital caliper.

Enamel blocks $(\mathrm{n}=10)$ were then divided into 4 groups and exposed to the beverages, as follows: NAT: natural grape juice (Campo Largo Juice Company, Campo Largo, PR, Brazil); IND: industrialized grape juice (Dell
Vale Kapo, The Coca Cola Company, SP Brazil); SOY: soy-based grape juice (Ades, Unilever); and CTRL (control): artificial saliva. Blocks were immersed for $2 \mathrm{~min}$, 3 times per day, for 9 days. During the whole time of the experiment, the enamel blocks were stored in artificial saliva. Sample size calculation was determined based on previous similar studies $(10,11)$. The artificial saliva contained the following composition: $150 \mathrm{mmol} / \mathrm{L} \mathrm{KCl}$, $1.5 \mathrm{mmol} / \mathrm{L} \mathrm{CaCl} 2$, and $0.9 \mathrm{mmol} / \mathrm{L} \mathrm{KH} 2 \mathrm{PO} 4$ in $100 \mathrm{~mL}$ of distilled water ( $\mathrm{pH}$ was adjusted to 7.0).

-Surface roughness analysis

For the roughness test, the specimens were attached to a glass slide with wax and individually analyzed with a roughness tester (SJ-210P Surftest; Mitutoyo, Kawasaki, Japan) equipped with a diamond needle with a 5 - $\mathrm{mm}$ radius at a constant speed of $0.5 \mathrm{~mm} / \mathrm{s}$. Before the readings, the roughness tester was calibrated according to the manufacturer's recommendations with a roughness standard. For each reading, a length of $2.5 \mathrm{~mm}$ was analyzed with a cutoff of $0.25 \mathrm{~mm}$. All readings were performed in duplicate. Three roughness parameters were evaluated: Ra, which is rated as the arithmetic average of the surface peaks and valleys; $\mathrm{Rz}$, which is the average between the peaks and valleys recorded in each of the test section; and Rq, which corresponds to the maximum distance between the highest peak and the deepest valley in the measurement path.

Data were analyzed using SPSS software (Statistical Package for the Social Sciences, version 20.0, IBM, USA). The dependent variables of the study were the roughness parameters that were initially tested for the distribution using Shapiro-Wilk normality test. To analyze differences between groups and between times (before and after), the average of each parameter (Ra, $\mathrm{Rz}$ and $\mathrm{Rq}$ ) was analyzed by two-way repeated measures ANOVA and Tukey's test. The significance level was $5 \%$.

$-\mathrm{pH}$ and acidity analysis

The grape juices were analyzed for $\mathrm{pH}$ and titratable acidity immediately after the packages are opened. The $\mathrm{pH}$ analysis was performed using a digital pHmeter (Phe$\mathrm{pR}+$, HANNA, Hanna Instruments SP, Brazil) previously calibrated with buffer solutions of $\mathrm{pH} 4.0$ and $\mathrm{pH}$ 7.0, according to the manufacturer's instruction. Measurements were initially carried out before the specimens are immersed.

The acidity was determined by beverage titration with sodium hydroxide $(0.1 \mathrm{~N})$. The $\mathrm{pH}$ range during the titration was monitored with a $\mathrm{pHmeter}$ until the $\mathrm{pH}$ rose to 5.5 and 7.0 for each sample. The volume of added sodium hydroxide was recorded in $\mathrm{mL}$.

The $\mathrm{pH}$ and acidity values to $\mathrm{pH} 5.5$ and $\mathrm{pH} 7.0$ of each juice (group) were analyzed for the distribution using Shapiro-Wilk normality test. Differences between groups were analyzed by one-way ANOVA and Tukey's 
test. The significance level was $5 \%$. The $\mathrm{pH}$, acidity $\mathrm{pH}$ 5.5 and acidity $\mathrm{pH} 7.0$ values were correlated by the Pearson's correlation coefficient.

\section{Results}

The surface roughness parameters analyzed ( $\mathrm{Ra}, \mathrm{Rq}$ and $\mathrm{Rz}$ ) performed similarly, indicating statistically significant differences only for time (between baseline and final measurements) ( $p=0.0001$ for $\mathrm{Ra}, p=0.0028$ for $\mathrm{Rq}$ and $\mathrm{p}=0.0002$ for $\mathrm{Rz}$ ). Groups ( $p=0.1758$ for $\mathrm{Ra}$, $p=0.1715$ for $\mathrm{Rq}$ and $p=0.1682$ for $\mathrm{Rz}$ ) and the double interaction groups*times ( $p=0.1131$ for $\mathrm{Ra}, p=0.1669$ for $\mathrm{Rq}$ and $\mathrm{p}=0.1262$ for $\mathrm{Rz}$ ) were not significant. Considering the measurements time, for all roughness parameters, final means were significantly higher than baseline mean values $(\mathrm{Ra}$ _baseline $=0.67 \mu \mathrm{m}$ and $\mathrm{Ra}$ _final $=1.10 \mu \mathrm{m} ; \mathrm{Rq} \_$baseline $=0.89 \mu \mathrm{m}$ and $\mathrm{Rq}$ final $=1.38$ $\mu \mathrm{m} ; \mathrm{Rz}_{-}$baseline $=3.01 \mu \mathrm{m}$ and $\mathrm{Rz}$ ffinal $=4.92 \mu \mathrm{m}$ ). The means and standard deviations for all groups, roughness parameters and time are shown in Table 1. It can be observed that for $\mathrm{Ra}$ and $\mathrm{Rq}$, significant differences between baseline and final values were observed only for natural grape juice (NAT). For Rz, significant differences between baseline and final values were observed only for natural industrialized grape juice (IND).

The $\mathrm{pH}$ and acidity values for $\mathrm{pH} 5.5$ and $\mathrm{pH} 7.0$ in each group are shown in Table 2. There was a statistically significant difference between groups $(p=0.02)$. The lower $\mathrm{pH}$ values were found in industrialized grape juice (IND) and natural grape juice (NAT), which did not differ between each other $(p=0.87)$. IND showed lower $\mathrm{pH}$ values than juice grape with soy milk (SOY) $(p=$ 0.031 ) (Table 2). The acidity values for $\mathrm{pH} 5.5$ and $\mathrm{pH}$
7.0 were strongly correlated by the Pearson's correlation $(\mathrm{r}=0.987)$, and weakly correlated with $\mathrm{pH}$ values $(\mathrm{r}=$ 0.33 and $\mathrm{r}=0.66$ for acidity in $\mathrm{pH} 5.5$ and $\mathrm{pH}$ and acidity $\mathrm{pH} 7.0$, respectively). The natural grape juice (NAT) showed the highest acidity values, differing from IND and SOY $(p<0.001)$. While the IND and SOY values did not differ between each other $(p=0.697)$, (Fig. 1).

\section{Discussion}

In this study, the surface roughness of primary teeth after exposure to different beverages was evaluated. In order to mimic what happens in the oral cavity, the teeth were stored in artificial saliva with appropriate concentrations of minerals, after exposure to acidic beverages. Such beverages have characteristics inherent to them and that are decisive for their erosive potential. Among these features the $\mathrm{pH}$ is extremely important. It is known that $\mathrm{pH}$ refers to the concentration of free hydrogen ions in solution, therefore it shows the actual availability of these ions to interact with the tooth surface (12). In this study the evaluation of beverages showed that their $\mathrm{pH}$ was less than 4.0, with average value of 3.7, being considered potentially erosive.

When $\mathrm{pH}$ decreases, the solubility of hydroxyapatite, both in enamel and dentine, increases. However, this is not the only factor in the cause of mineral dissolution by erosion. In this study, $\mathrm{pH}$ values are weakly correlated to the acidity values. This could be explained analyzing other variables such as amount of titratable acids, type of acids, buffer capacity and chelating properties. Naturally, grape contains tartaric and maleic acids. Other acids can be added in industrialized beverages, acting as anti-oxidants, such as ascorbic acid and $\mathrm{pH}$ regulators,

Table 1: Means (SD) of the roughness parameters $(\mu \mathrm{m})$ at baseline and after exposure to the different beverages and artificial saliva.

\begin{tabular}{|c|c|c|c|c|c|c|}
\hline \multirow[t]{3}{*}{ Beverage } & \multicolumn{6}{|c|}{ Roughness parameter $(\mu \mathrm{m})$} \\
\hline & \multicolumn{2}{|c|}{$\mathrm{Ra}$} & \multicolumn{2}{|c|}{$\mathrm{Rq}$} & \multicolumn{2}{|c|}{$\mathrm{Rz}$} \\
\hline & Baseline & Final & Baseline & Final & Baseline & Final \\
\hline $\begin{array}{l}\text { NAT (natural } \\
\text { grape juice) }\end{array}$ & $0.63(0.22)^{a}$ & $1.54(1.00)^{b}$ & $0.87(0.30)^{\mathrm{a}}$ & $1.96(1.31)^{b}$ & $3.07(1.17)^{\mathrm{ab}}$ & $6.09(3.03)^{b}$ \\
\hline $\begin{array}{l}\text { IND (industrial- } \\
\text { ized grape juice) }\end{array}$ & $0.64(0.32)^{a}$ & $1.19(0.72)^{\mathrm{ab}}$ & $0.89(0.55)^{\mathrm{a}}$ & $1.45(0.80)^{a b}$ & $2.88(1.31)^{\mathrm{a}}$ & $5.92(3.49)^{b}$ \\
\hline $\begin{array}{l}\text { SOY (soy-based } \\
\text { grape juice) }\end{array}$ & $0.78(0.28)^{a b}$ & $1.00(0.56)^{\mathrm{ab}}$ & $1.00(0.45)^{a b}$ & $1.21(0.65)^{a b}$ & $3.38(1.41)^{\mathrm{ab}}$ & $4.60(2.69)^{a b}$ \\
\hline $\begin{array}{c}\text { CTRL (artificial } \\
\text { saliva) }\end{array}$ & $0.63(0.55)^{a}$ & $0.73(0.46)^{a}$ & $0.81(0.62)^{\mathrm{a}}$ & $0.96(0.63)^{\mathrm{ab}}$ & $2.74(1.78)^{a}$ & $3.17(1.76)^{a b}$ \\
\hline
\end{tabular}

For each parameter, the same superscript indicates that there was no statistically significant difference between groups and times. 
Table 2: Means (SD) of $\mathrm{pH}$ and acidity values for $\mathrm{pH} 5.5$ and $\mathrm{pH} 7.0$ for the different beverages.

\begin{tabular}{|c|c|c|c|}
\hline Beverages & pH & \multicolumn{2}{|c|}{ Acidity } \\
\cline { 3 - 4 } & & pH 5.5 & pH 7.0 $^{-1}$ \\
\hline NAT (natural grape juice) & $3.71(0.31)^{\mathrm{ab}}$ & $2.49(0.83)^{\mathrm{a}}$ & $3.44(0.82)^{\mathrm{a}}$ \\
\hline IND (industrialized grape juice) & $3.67(0.36)^{\mathrm{a}}$ & $0.74(0.24)^{\mathrm{b}}$ & $1.09(0.28)^{\mathrm{b}}$ \\
\hline SOY (soy-based grape juice) & $3.90(0.34)^{\mathrm{b}}$ & $0.96(0.24)^{\mathrm{b}}$ & $1.53(0.46)^{\mathrm{b}}$ \\
\hline
\end{tabular}

For each column, the same superscript indicates that there was no statistically significant difference between groups.

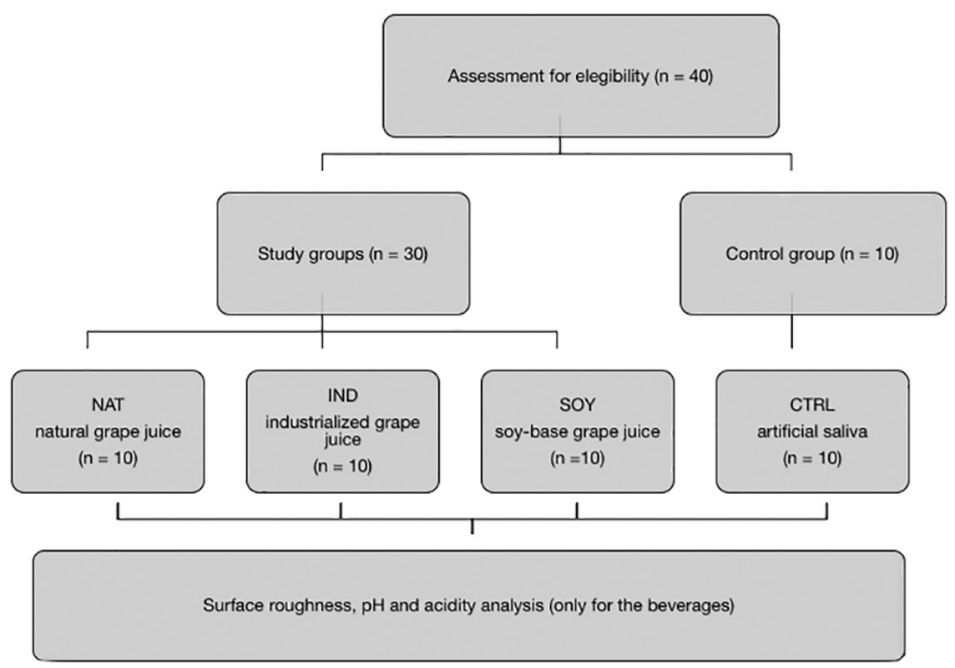

Fig. 1: CONSORT flow diagram of the study.

such as citric acid. The presence of these components may be related to the time of development of dental erosion and allergic reactions (13).

The presence of phosphate, calcium and fluoride in the composition of beverages should also be considered (12). Undissociated organic acids should also be taken into account $(7,15,16)$. The measurement of these in beverages or any solutions is performed by means of titration, a technique calls for the use of a base, $\mathrm{NaOH}$, to titrate the acidic solution. The greater the amount of $\mathrm{NaOH}$ added to the analyzed sample, the higher is its acidity.

In the present study, the natural grape juice showed the highest acidity values, as it required a statistically higher amount of $\mathrm{NaOH}$ so that the $\mathrm{pH}$ rose to 5.5 and $7.0(p<$ 0.001 ) compared to the other two groups. However, the obtained results did not correlate to the acidity observed in this juice. Once there are differences between the erosive potential of beverages and their $\mathrm{pH}$ and acidity, the enamel surface analysis is very important to determine the action of the juices on its surface (17-20). In this study, for the three roughness parameters evaluated, no statistically significant differences among the groups (NAT, IND, SOY and CTRL). The low pH as well as the low calcium and fluoride ion concentration indicates higher erosive potential (21). A commonly investigated modification has been the use of additives, mostly salts containing calcium and/or phosphate ions. They act based on the common ion effect, where the driving force for dental surface dissolution can be decreased by the saturated state of the beverage with respect to the calcium and phosphate ions (20).

In this study the natural grape juice (NAT) showed the highest acidity values, statistically differing from IND and SOY $(p<0.001)$, while IND and SOY values did not differ between them $(p=0.697)$. However, other studies report that the whole juice showed the highest titratable acidity, significantly differing from the other flavors (2225).

An important point to be considered is the exposure time of the enamel samples in the juice. Analyzing the erosive effect of different grape juices on the surface roughness, it was noted that only after 15 days of exposure the grape juices caused an increase in surface roughness $(14,26)$. In this study, even without statistical difference, it was observed that a 9-day exposure to beverages had an increase in surface roughness of specimens evaluated and it is assumed that, if the exposure time were greater, the difference would be significant.

Considering that, parents should be aware about heal- 
thy life habits of their children. There is an increase in consumption of natural juices, which replace soft drinks; however, data from previous studies and this study showed that these beverages cause tooth enamel demineralization and should be consumed with caution $(12,27,28)$. Thus, although tooth erosion is multifactorial, the frequent consumption of foods with low $\mathrm{pH}$ and high acid content can be a determining factor in its evolution.

\section{Conclusions}

It can be concluded that all grape juices tested influenced in the roughness parameters of primary enamel, even if they did not differ from the control group. Grape juices, especially natural, may have erosive capacity, changing the surface roughness of primary dental enamel. $\mathrm{pH}$ had a weak correlation with the acidity values and the juice with highest acidity (natural grape juice) showed greater erosive.

\section{References}

1. Asher C, Read MJ. Early enamel erosion in children associated with the excessive consumption of citric acid. Br Dent J. 1987;162:384-7.

2. Järvinen VK, Rytömaa II, Heinonen OP. Risk factors in dental erosion. J Dent Res. 1991;70:942-7.

3. Cheng R, Yang H, Shao MY, Hu T, Zhou XD. Dental erosion and severe tooth decay related to soft drinks: a case report and literature review. J Zhejiang Univ Sci B. 2009;10:395-9.

4. Ayad MF, Johnston WM, Rosenstiel SF. Influence of dental rotary instruments on the roughness and wettability of human dentin surfaces. J Prosthet Dent. 2009;102:81-8.

5. Lintojua LA, Andreana S, Bush PJ, Cohen RE. Tooth wear: Attrition erosion and abrasion. Quintessence Int. 2003;34:435-46.

6. Lussi A (ed). Dental Erosion. Monogr Oral Sci. 2006;20:32-43.

7. Lussi A, Jaegger T, Zero D. The role of diet in the etiology of tooth erosion. Caries Research. 2004;38:34-44.

8. Bamise CT, Oziegbe EO. Laboratory analysis of $\mathrm{pH}$ and naturalizable acidity of commercial citrus fruits in Nigeria. Adv Biol Res. 2013;7:872-6.

9. Kimyai S, Savadi-Oskoee S, Ajami AA, Sadr A, Asdagh S. Effect of three prophylaxis methods on surface roughness of giomer. Med Oral Patol Oral Cir Bucal. 2011;16:e110-4.

10. Tabari M, Alaghemand H, Qujeq D, Mohammadi E. Effect of popping chocolate and candy on enamel microhardness of primary and permanent teeth. J Int Soc Prev Community Dent. 2017;7:370-6.

11. Bolan M, Ferreira MC, Vieira RS. Erosive effects of acidic center-filled chewing gum on primary and permanent enamel. J Indian Soc Pedod Prev Dent. 2008;26:149-52.

12. Barbour ME, Rees GD. The role of erosion, abrasion and attrition in tooth wear, J Clin Dent 2006;17:88-93

13. Taji S, Seow WK. A literature review of dental erosion in children. Aust Dent J. 2010;55:358-67; quiz 475.

14. Gonçalves GKM, Guglielmi CAB, Corrêa FNP, Raggio DP, Côrrea MSNP. Erosive potential of different types of grape juices Braz Oral Res. 2012;26:457-63.

15. Brancher JA, Gill AC, Dalmolin N, Torres MF, Guimarães AT, Losso EM. In vitro analysis of $\mathrm{pH}$ and titratable acidity of yogurts and milk beverages. Braz Res Pediatric Dent Integrat Clinic. 2014;14:8996.

16. Eccles JD. Erosion affecting the palatal surfaces of upper anterior teeth in young people. Br Dent J 1982;152:375-8.

17. Rajavardhan K, Sankar A, Kumar M, Kumar KR, Pranitha K, Kishore KK. Erosive potential of cola and orange fruit juice on tooth colored restorative materials. Ann Med Health Sci Res. 2014; 4::S20812.
18. Silva TAA, Sampaio CS, Furtado JEAS, Abílio GMF, Xavier AFC, Cavalcanti AL. Evaluation of erosive potential of soy-based drinks. Rev Bras Ci Saúde. 2010;14:109-114.

19. Smith AJ, Shaw L. Baby fruit juice and tooth erosion. Br Dent J. 1987;162:65-7.

20. Scaramucci T, Hara AT, Zero DT, Ferreira SS, Aoki IV, Sobral MA. In vitro evaluation of the erosive potential of orange juice modified by food additives in enamel and dentine. J Dent. 2011;39:841-8.

21. Jager DH, Vieira AM, Ruben JL, Huysmans MC. Influence of beverage composition on the results of erosive potential measurement by different measurement techniques. Caries Res 2008;42:98-104.

22. Li H, Zou Y, Ding G. Dietary factors associated with dental erosion: a meta-analysis. PLoS One. 2012;7:e42626.

23. Lussi A. Erosive tooth wear - a multifactorial condition of growing concern and increasing knowledge. Monogr Oral Sci. 2006;20:1-8.

24. Maganur PC, Prabhakar AR, Satish V, Namineni S, Kurthukoti A. Erosive effect of soft drink and fresh fruit juice on restorative materials. World J Dent. 2013;4:32-40.

25. Nirmala S, Subba Reddy VV. A comparative study of $\mathrm{pH}$ modulation and trace elements of various fruit juices on enamel erosion: an in vitro study. J Indian Soc Pedod Prev Dent. 2011;29:205-15.

26. Lussi A, Kohler N, Zero D, Schaffner M, Megert B. A comparison of the erosive potential of different beverages in primary and permanent teeth using an in vitro model. Eur J Oral Sci. 2000;108:110-4.

27. Ganss C, Lussi A. Diagnosis of erosive tooth wear. Monogr Oral Sci. 2014;25:22-31

28. Huysmans MC, Chew HP, Ellwood RP. Clinical studies of dental erosion and erosive wear. Caries Res. 2011;45:60-8.

\section{Conflict of interest}

The authors declare that they have no conflict of interest. 